Ebisu Ebisu

Études japonaises Études japonaises

48 | automne-hiver 2012

Naissance d'une revue féministe au Japon : Seitō

(1911-1916)

\title{
Chronologie interne à Seitō
}

Établie par Christine LÉVY

\section{Christine Lévy}

\section{OpenEdition}

\section{Journals}

Édition électronique

URL : http://journals.openedition.org/ebisu/669

DOI : 10.4000/ebisu.669

ISSN : 2189-1893

Éditeur :

Institut français de recherche sur le Japon (UMIFRE 19 MAEE-CNRS), Maison franco-japonaise

Édition imprimée

Date de publication : 1 septembre 2012

Pagination : 167-171

ISSN : 1340-3656

\section{Référence électronique}

Christine Lévy, "Chronologie interne à Seitō », Ebisu [En ligne], 48 | automne-hiver 2012, mis en ligne le 20 mars 2014, consulté le 20 avril 2019. URL : http://journals.openedition.org/ebisu/669 ; DOI :

10.4000/ebisu.669 


\section{Chronologie interne à Seitō}

Établie par Christine LÉvY

Les textes suivis d'un astérisque * sont traduits en français et sont à paraître.

\section{Première année de Seitō}

mars Ikuta Chōkō, traducteur de Nietzsche, encourage Hiratsuka Haru (infra Raichō) à créer une revue littéraire féminine.

30 mai Hiratsuka Raichō et Yasumochi Yoshi impriment secrètement les statuts de l'association Seitōsha dans la résidence pour étudiantes de l'École supérieure de jeunes filles Joshi daigakkō (Raichō avait été exclue de l'association des anciennes élèves Ōfūkai).

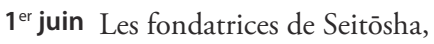
Nakano Hatsu, Yasumochi Yoshi, Kiuchi Tei, Hiratsuka Raichō et Mozume Kazu se réunissent chez cette dernière.

6 juin Raichō rend visite à la poétesse Yosano Akiko pour lui demander une contribution pour le premier numéro de la revue.
21 juin La parution de Seitō est annoncée dans la presse : Yomiuri shinbun, Tōkyō Asabi shinbun, Kokumin shinbun.

7 août Raichō demande à Naganuma Chieko de concevoir la couverture de Seitō.

sept. Parution du premier numéro de Seitō tiré à 1000 exemplaires, avec le poème de Yosano Akiko Sozorogoto (Flânerie) et le Manifeste de Hiratsuka Raichō "À l'origine, la femme était le soleil* ". Seitōsha compte alors 30 membres, dont 7 membres bienfaitrices, des femmes connues dans le milieu littéraire.

Première représentation d'Une Maison de poupée d'Ibsen avec Matsui Sumako dans le rôle de Nora, à l'université Waseda.

oct. Le second numéro comprend des articles sur la pièce d'Ibsen, Hedda Gabler. 


\section{Seconde année de Seitō}

jan. Parution du supplément spécial sur Nora, l'héroïne d'Une Maison de poupée.

fév. Seitōsha compte 56 membres.

mars Parution chez l'éditeur Hakubunkan du recueil de douze nouvelles (Keishū shōsetsu jūnihen) écrites par des membres de Seitōsha, sous la direction d'Okada Yachiyo.

avril Numéro consacré aux romans (nouvelles).

Première interdiction de vente de Seitō qui contient la nouvelle $L a$ Lettre* d'Araki Iku.

Première réunion du groupe d'études de Seitō, avec des conférenciers invités.

mai La pièce de Sudermann, Magda (Kokyō, pays natal en japonais), jouée par la troupe de Bungei kyōkai, est interdite de représentation pour atteinte morale à la famille.

Yomiuri shinbun publie une série de 25 articles sur la «femme nouvelle».

juin Un dossier spécial est consacré à Magda dans Seitō.

juil. Affaires dites «Goshiki no sake " (cocktail aux cinq couleurs) et « Yoshiwara tōrō » (visite au quartier de plaisir de Yoshiwara) : des articles à sensation attaquent les «femmes nouvelles".

août Seitō publie la correspondance intime entre Hiratsuka Raichō et Otake Kōkichi (Beniyoshi). oct. Premier anniversaire de Seitō, fêté à Uguisudani. Le tirage est passé à 3000 exemplaires.

Raichō publie un article dans lequel Higuchi Ichiyō est qualifiée de femme " ancienne ".

Tōkyō nichinichi shinbun publie six articles intitulés "Atarashigaru onna " (Les femmes qui se veulent nouvelles).

Articles sur la femme nouvelle également dans la revue Shinchō.

nov. Itō Noe commence à aider au travail éditorial de Seitō.

\section{Troisième année de Seitō}

jan. Raichō commence à traduire Ellen Key.

Premier supplément spécial de Seitō sur les femmes nouvelles et la question féminine.

Raichō publie dans Chūō kōron "Watashi wa atarashii onna de aru " (Je suis une femme nouvelle) pour son numéro spécial consacré aux femmes nouvelles. Certains des articles sont traduits en anglais pour le Japan Times.

fév. Projet de la création d'un groupe d'étude littéraire au sein de Seitō.

15 fév. La première conférence publique de Seitōsha. Raichō ouvre la séance, suivie des conférences successives d'Itō Noe, Ikuta Chōkō, Iwano Hōmei.

sept. Adhésion d'Itō Noe. 
Parution du premier recueil de romans Seitō shösetsu-shī dai ichi publié par Seitōsha. La majorité des œuvres traite du conflit dans les rapports entre les hommes et les femmes. Le projet était de publier une fois par an ce type de recueil, mais il ne connut pas de suite.

Interdiction du second numéro consacré aux femmes nouvelles et à la question féminine, dans lequel figure l'article de la socialiste Fukuda Hideko "Solution à la question féminine*».

mars Nishikawa Fumiko, Miyazaki Teruko, Kimura Komako créent la Nouvelle association de la vraie femme (Shin-shinfujin-kai) pour se démarquer des critiques émises à l'encontre de Seitō par les média.

avril Raichō publie dans Seitō "Aux femmes de ce monde*" dans lequel elle critique le mariage en tant qu'institution.

20 avril Le ministère de l'Éducation décide d'interdire dans les revues féminines les publications de textes critiquant le principe de la « bonne épouse, mère avisée ". Seitō est la principale publication visée.

25 avril Les membres de Seitō sont convoquées par le bureau supérieur de la censure de la police pour atteinte aux vertus de la femme à cause de l'article de Raichō "Aux femmes de ce monde*".
Seitō reçoit des menaces de mort de la part d'un parti qui se dénomme Howaito kyappu-tō (Parti des cagoules blanches) : Iwano Kiyo, Hayashi Chitose, Itō Noe, Araki Iku y sont nommément menacées.

mai Ikuta Chōkō, mentor de Raichō, prend ses distances par rapport à la revue.

Louvrage de Raichō, Marumado yori (D'une fenêtre ronde), est interdit à la vente.

juin Marumado yori paraît sous le titre Tozashi aru mado nite (D’une fenêtre fermée) amputé de l'article "Aux femmes de ce monde* .

La revue Taiyō publie un numéro spécial intitulé "Kinji no fujin mondai kō » (Réflexions sur la question féminine aujourd'hui).

juil. Le mensuel Chūō kōron publie un numéro spécial sur la question féminine, qui inclut un dossier consacré à Hiratsuka Raichō.

oct. Modification des statuts de Seitōsha : le premier article affirme que l'association se donne pour but l'éveil de la conscience des femmes, le développement de la vocation personnelle de chacune et la naissance des talents féminins. Le statut des membres est modifié dans le sens d'un engagement plus important envers l'association. Un appel est lancé pour des dons de soutien et la création d'un groupe de membres donatrices est décidée. 


\section{Quatrième année de Seitō}

jan. Raichō quitte son foyer familial et commence à vivre avec Hiroshi, son amant.

Nishizaki (Ikuta) Hanayo publie « Des difficultés de la vie amoureuse et de la vie quotidienne*".

Supplément à Seitō sur La profession de Mme Warren, de George Bernard Shaw.

mars Otake Kōkichi (Beniyoshi) qui a quitté Seitō, lance la revue Safuran (publication jusqu'en août).

Itō Noe traduit La tragédie de l'émancipation de la fermme d'Emma Goldman.

avril Numéro spécial de Seitō consacré aux romans et aux nouvelles.

Ikuta Chōkō et Morita Sōhei lancent la revue Hankyō (Résonance).

sept. L'article « Taberu koto to teisō to " (" Manger et rester chaste ») d'Ikuta Hanayo, publié dans Hankyō, lance la polémique sur la question de la chasteté.

oct. Raichō confie la rédaction éditoriale de Seitō à Itō Noe.

déc. Yasuda Satsuki publie dans Seitō "Vivre et rester chaste* " en réponse à Ikuta Hanayo.

\section{Cinquième année de Seitō}

jan. La direction de la rédaction et de l'édition passe définitivement aux mains d'Itō Noe.

Raichō publie «Seitō to watashi : Seitō o Noe san ni oyuzuri suru ni tsuite » (Seitō et moi : à propos de la cession de Seitō à Itō Noe).

Réponse d'Itō Noe « Seitōo hikitsugu ni tsuite (À propos de la succession à la direction de Seitō) ". Nouvelle directive dans l'organisation de Seitō qui n'a plus « ni statuts, ni direction éditoriale, ni principes". Les non-membres de Seitō peuvent proposer des textes, mais Itō Noe est seule responsable de la sélection des textes à publier.

fév. Itō Noe publie « Diverses pensées sur la chasteté* ".

Ikuta Hanayo publie dans Hankyō une réponse au texte de Yasuda Satsuki.

mars Raichō publie "Shojo no kachi " (La valeur de la virginité) dans Shinkōron. 
avril Ōsugi Sakae publie "Shojo to teisō to shūchi to » (La virginité, la chasteté et la pudeur) dans Shinköron, commentaire sous forme de lettre à Itō Noe sur le débat.

mai Numéro spécial consacré aux romans et aux nouvelles.

juin Harada Satsuki publie D'une fermme en prison à son homme*, le numéro de Seitō est interdit, la nouvelle lance la polémique sur l'avortement (troisième interdiction de la revue).

Itō Noe publie "Lettre à Mme Nogami Yaeko*».

juil. La rédaction sollicite l'avis du plus grand nombre possible des membres de Seitō sur la question de l'avortement.

août Itō Noe accouche de son second enfant, Seitō ne paraît pas.

sept. Raichō publie « Lettre à Noe : à propos du conflit entre la vie de l'individu et la vie en tant qu'être sexué* ".

nov. Saiga Koto publie "Senka " (Désastres de la guerre), seul texte antibelliciste de Seitō.

déc. Itō Noe publie «À propos des œuvres sociales des Japonaises : arrogance, intolérance, inconséquence* ${ }^{*}$.

Raichō accouche de son premier enfant.

\section{Sixième année de Seitō}

jan. Yamakawa Kikue publie " Réponse à Itō Noe au sujet des œuvres sociales des Japonaises* ».

Réponse de Noe : "Aoyama Kikue shi ni " (À Mme Aoyama [Yamakawa] Kikue).

Création de la revue féminine Fujin kōron (Débat public des femmes, encore publiée de nos jours).

fév. Yamakawa Kikue répond à Itō Noe "Sara ni ronshi o akasuni » (Pour éclairer la polémique).

Fin de la publication de Seitō, 52 livraisons depuis 1911.

Durant cette période, environ deux cents femmes ont contribué d'une manière ou d'une autre à des publications au sein de la revue. 